NBER WORKING PAPER SERIES

\title{
GENERATING EVIDENCE TO GUIDE MERGER ENFORCEMENT
}

\author{
Orley C. Ashenfelter \\ Daniel Hosken \\ Matthew Weinberg \\ Working Paper 14798 \\ http://www.nber.org/papers/w14798
NATIONAL BUREAU OF ECONOMIC RESEARCH
1050 Massachusetts Avenue
Cambridge, MA 02138
March 2009

We would like to thank Chris Taylor for his comments. The views expressed herein are those of the author(s) and do not necessarily reflect the views of the National Bureau of Economic Research.

NBER working papers are circulated for discussion and comment purposes. They have not been peerreviewed or been subject to the review by the NBER Board of Directors that accompanies official NBER publications.

(C) 2009 by Orley C. Ashenfelter, Daniel Hosken, and Matthew Weinberg. All rights reserved. Short sections of text, not to exceed two paragraphs, may be quoted without explicit permission provided that full credit, including $(\mathrm{C}$ notice, is given to the source. 
Generating Evidence to Guide Merger Enforcement

Orley C. Ashenfelter, Daniel Hosken, and Matthew Weinberg

NBER Working Paper No. 14798

March 2009

JEL No. K21,L1,L4

\section{ABSTRACT}

The challenge of effective merger enforcement is tremendous. U.S. antitrust agencies must, by statute, quickly forecast the competitive effects of mergers that occur in virtually every sector of the economy to determine if mergers can proceed. Surprisingly, given the complexity of the regulators task, there is remarkably little empirical evidence on the effects of mergers to guide regulators. This paper describes the necessity of retrospective analysis of past mergers in building an empirical basis for antitrust enforcement, and provides guidance on the key measurement issues researchers confront in estimating the price effects of mergers. We also describe how evidence from merger retrospectives can be used to evaluate the economic models used to predict the competitive effects of mergers.

Orley C. Ashenfelter

Industrial Relations Section

Firestone Library

Princeton University

Princeton, NJ 08544

and NBER

c6789@princeton.edu

Daniel Hosken

Federal Trade Commission

600 Pennsylvania Avenue, NW

Washington, DC 20580

dhosken@ftc.gov
Matthew Weinberg

Federal Trade Commission

Mail Stop 4264

600 Pennsylvania Avenue, NW

Washington, DC 20580

mweinberg@ftc.gov 


\section{Introduction}

The Federal Trade Commission and the Department of Justice attempt to block or modify only those mergers that would reduce consumer welfare. The challenge of effective enforcement is enormous. The antitrust agencies have relatively little time to evaluate the likely impact of large changes in market structure on consumer welfare. Further, mergers occur in virtually every sector of the economy forcing teams of economists and lawyers to confront very different institutional details from one case to the next. Surprisingly, given the complexity of the regulators task, there is remarkably little empirical evidence on the effects of mergers to guide regulators. Empirical evidence on the price effects of consummated mergers can both determine whether past antitrust enforcement was applied correctly, and aid regulators in developing more effective techniques to forecast the likely effects of mergers on competition. This paper describes the necessity of retrospective analysis of past mergers in building an empirical basis for antitrust enforcement, and provides guidance on the key measurement issues researchers confront in estimating the price effects of mergers. We also describe how evidence from merger retrospectives can be used to evaluate the economic models used to predict the competitive effects of mergers.

Determining the price effects of consummated mergers is difficult for several reasons. First, calculating the effect of a merger on prices necessitates knowledge of what prices would have been had the merger not occurred. These counterfactual prices are inherently unobservable, and assumptions that may be questionable must be made in order to identify and estimate these effects. Further, prices are often difficult to measure in available datasets. Difficulties in measuring prices can have important consequences on the results of merger retrospectives. Finally, and as noted by Carlton (2009) and Ashenfelter and Hosken (2008), it is difficult to generalize from the results of even a large number of retrospective studies because only the price effects of consummated mergers are observed. Mergers that are consummated represent a selected sample of all possible mergers, not a random sample. Fortunately, a well designed study can overcome these three difficulties and much of this paper describes different approaches for doing so. 
In addition to identifying whether past antitrust enforcement was at its proper level, retrospective analysis can also directly improve future antitrust decision making. Due to the costliness of dissolving consummated mergers, U.S. antitrust policy towards mergers is almost entirely prospective. The government must forecast how each potential merger would affect prices and hence consumer surplus. A large number of retrospective studies could aid government decision making by revealing what observable characteristics of mergers are associated with price increases. Further, retrospective evidence provides a useful method for evaluating economic models used to forecast the competitive effects of mergers. These methods include financial event studies, retrospective analysis from non-merger related activity, and simulations from structural oligopoly models (merger simulations). A chief benefit of these methods is that they generate explicit predictions of the competitive effects of mergers, and in the case of merger simulations an explicit prediction of the price effect. Further, the assumptions underlying these models are explicitly stated and, thus, can be subjected to rigorous review. In contrast, the analysis of the evidence traditionally used in merger review, testimony of market participants and company documents, is inherently more subjective. Because economic models generate explicit predictions of the competitive effects of mergers, it is relatively straightforward (though resource intensive) to evaluate their performance with retrospective evidence. If these tools are proven effective, they could lead to a more efficient, objective, and accurate merger review process.

The rest of the paper is structured as follows. Section II describes the decision problem of the antitrust authorities and discusses extant retrospective evidence, Section III describes the key issues in estimating the price effects of consummated mergers, and Section IV describes the economic models used to forecast price effects. Section V concludes.

\section{Antitrust Decision Making}

The Clayton Act forbids mergers that would "substantially reduce competition". The U.S. Federal Trade Commission and the Antitrust Division of the U.S. Department of Justice enforce the Clayton Act, and the protocol by which they do so is given in the Hart-Scott-Rodino Act (HSR Act). In practice, the agencies seek to block mergers that 
would reduce consumer surplus, primarily through higher prices. The HSR Act requires parties engaged in commerce and acquiring assets valued at more than $\$ 65.2$ million to file an intention to merge with the FTC and DOJ before coordinating their activities. The firms must then wait while the merger is allocated to one of the agencies and investigated for potential anticompetitive effects.

Because it is undesirable to delay efficient mergers, the HSR effectively forces the U.S. antitrust agencies to make decisions under strict legislated time constraints. The HSR Act gives the government 30 days for its initial investigation. If the merger is potentially problematic, the government issues a "second request" to the merging parties. The second request is a detailed subpoena requesting documentary evidence (including quantitative data) that is relevant to the government investigation. While the merging parties do not face any formal time deadline to comply with the second request, it is in their interests to comply quickly so as not to delay the transaction more than necessary. After all documents are submitted for the second request, the government has a final 30 days to review the case.

The 1992 FTC/DOJ Horizontal Merger Guidelines provide the analytic framework used in merger review. In the course of its investigation, the agencies must define geographic and product markets, and then predict competitive effects, efficiencies and the likelihood of entry. The information with which the government makes these decisions is limited. Often government attorneys and economists are limited to the information contained in company documents and the testimony of merging firms' executives and other market participants. When the merging parties have high quality price, quantity, and or revenue data, it is possible to use demand estimates and oligopoly models to help define product and geographic markets and simulate the price effects of mergers.

The sheer magnitude of the number and variety of merger filings each year demonstrates the difficulties facing antitrust enforcers. Figure 1 plots the total number of merger filings, measured on the left vertical-axis, and the total number of second requests, measured on the right vertical-axis. While the vast majority of mergers are consummated without modification or review, on average over the past decade, the agencies conducted major investigations of mergers (that generated a second requests) 71 
times a year. ${ }^{2}$ Further, over the past decade, these mergers took place in roughly 80 different industries, as defined by 3-digit NAICS codes. ${ }^{3}$

Figure 1: Hart Scott Rodino Filings and Second Requests,

1998-2007

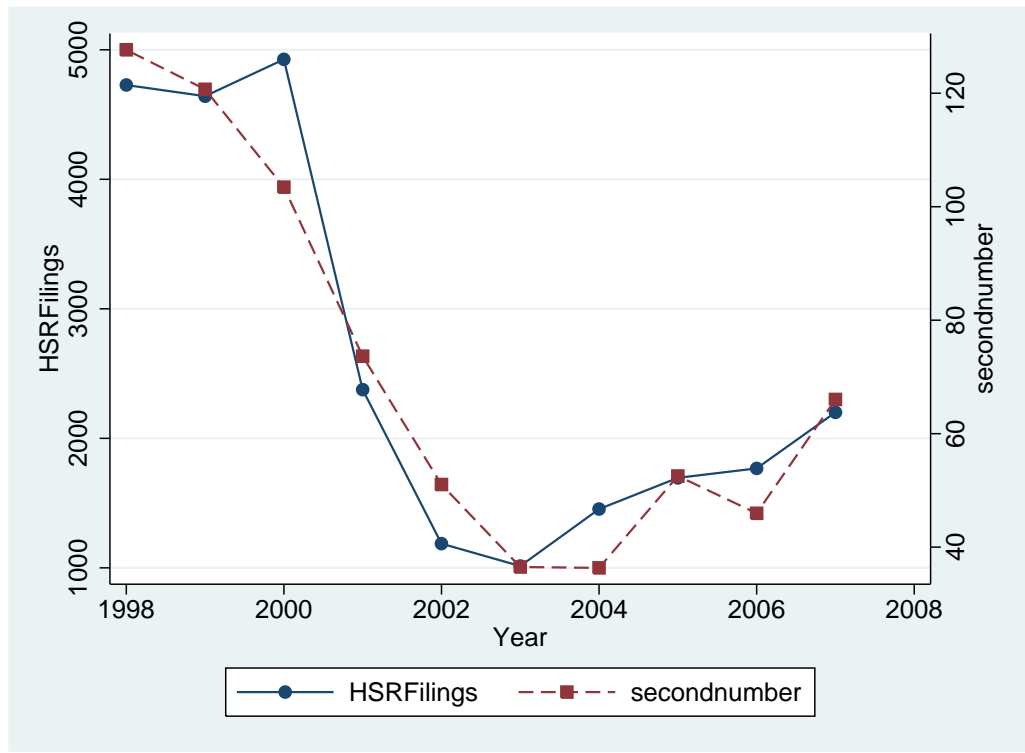

Thus, not only do the agencies have to review a large number of mergers in a short time period, they often are forced to make decisions with only limited exposure to the industry. Industries differ dramatically in institutional detail critical for merger analysis. Mergers take place in markets that differ in seller and buyer concentration, substitutability of different products, and barriers to entry.

Studies of the price effects of consummated mergers provide a useful aid for government decision making. Currently, there are about twenty published merger retrospectives, see Pautler (2001), Hunter et al. (2008), and Weinberg (2008) and for recent surveys. The mergers that have been studied are not representative of consummated mergers. Instead of estimating the average price effect of a

\footnotetext{
${ }^{2}$ HSR filing and second request figures are taken from the Hart-Scott-Rodino Annual Reports to Congress. The drop in the number of filings and second requests after 2001 is due to both the end of a merger wave and also an increase in the HSR filing threshold from transactions valued at \$15 million or more to \$59.8 million or more.

${ }^{3}$ 3-digit NAICS codes for the merging parties are reported in HSR Premerger Notification and Report Forms.
} 
merger, most studies focus on mergers that were likely on the enforcement margin. For example, Ashenfelter and Hosken (2008) focus on five consumer product market mergers that took place in highly concentrated markets. Thus the results of these studies should be interpreted as measuring the effectiveness of specific (non) enforcement decisions and not as the average price effect caused by a consummated merger. In addition, most existing studies have taken place in four industries where pricing data are publicly available: airlines, banking, hospitals, and petroleum. The vast majority of merger retrospectives find evidence of price increases, at least in the short period they observe post-merger pricing. However, the number of merger studies is not large, they cover a time span of roughly 30 years, and only a handful of industries have been studied. That being said, the main implication of this research is that mergers in concentrated markets can lead to price increases. Given our limited knowledge it is impossible to draw broader conclusions about the effectiveness of enforcement or specific guidance as to what market characteristics are more likely to result in anticompetitive mergers.

\section{Generating Evidence to Improve Decision Making}

Merger retrospectives are useful for both evaluating past antitrust policy and in learning what types of mergers lead to increases in consumer prices. As in all empirical analysis, for a study to yield useful results it is critical to have a sensible design and data sufficient to answer the question of interest. Below we highlight what we see as the key issues in estimating the price effects of the merger. First, and of primary importance, is developing a reasonable estimate of what prices in an industry would be had the merger not occurred. Second, we discuss the importance of identifying a reasonable measure of

price. Finally, we discuss issues involved in identifying the time period in which we think the price effects of the merger would manifest themselves.

\section{Modeling the Counterfactual}

The goal of a merger retrospective is straightforward: learn if prices changed as the result of a merger. A decrease in prices implies that the merger was efficient, and an increase in prices implies that the merger increased market power to the detriment of consumers (assuming no coincident increase in quality). The major issue in estimating 
the price effect of a merger, as with any evaluation of a change in a market using nonexperimental data, is the method used to control for other confounding factors that may also have changed at the time of the event. Of especial concern in a merger setting is the effect of possible changes in demand or costs unrelated to the merger that may cause prices to change.

For example, suppose a merger of two large gasoline refiners operating in the U.S. Midwest was consummated on January $1^{\text {st }} 2008$. The antitrust agencies are subsequently asked by the U.S. Congress to determine if that merger adversely affected consumers. In response to this request the antitrust agencies ask their economists to measure the price effect of this merger. The antitrust economists find that prior to the merger gasoline prices in the Midwest were roughly \$3.03 a gallon the week before the merger was consummated, rose to $\$ 4.03$ six months after the merger date, and then fell to $\$ 1.57$ at the end of 2008. ${ }^{4}$ Would it be correct to conclude from this price pattern that directly following the merger the gasoline refiners exploited their market power causing price to increase about $\$ 1$ a gallon, however, by the end of the year (after the firms had time to integrate their facilities) the efficiencies were so great that prices fell to nearly $50 \%$ measured relative to prices just before the merger was consummated? This conclusion seems unlikely. Variability in gasoline prices is largely caused by changes in crude prices. Crude oil prices were roughly $\$ 96$ a barrel on December 31, 2007, \$140 a barrel on June $30^{\text {th }}, 2008$, and $\$ 39$ a barrel on December 31, 2008. ${ }^{5}$ Thus, in this hypothetical merger retrospective relying on a simple "before and after" estimator would yield highly misleading results about the price effects of the hypothetical merger because the technique being used did not control for other factors (crude oil prices) that are important inputs into the production of gasoline. While this example is highly simplified, it illustrates why a researcher must control for factors unrelated to the merger that may have affected prices. In most studies, these factors typically consist of shocks to supply and demand.

In a merger retrospective, the price effect of the merger is defined as the difference between the observed price following the merger and what prices would have

\footnotetext{
${ }^{4}$ All prices are taken from the Energy Information Administration’s website, http://www.eia.doe.gov/.

${ }^{5}$ Prices of West Texas Crude, the most commonly traded crude in the US.
} 
been "but for" the merger. The typical merger retrospective assumes that there is a reduced form pricing relationship similar to equation (1) below in the markets affected by mergers.

$$
\text { (1) } \mathrm{P}_{\mathrm{Mt}}=\alpha_{M 0}+\gamma_{\mathrm{t}}+\alpha_{\mathrm{M} 1} \text { Post }_{\text {Merger }}+\varepsilon_{\mathrm{Mt}}
$$

These studies assume that the price in the market affected by a merger $\left(\mathrm{p}_{\mathrm{Mt}}\right)$ is a function of costs and demand factors which vary over time $\left(\gamma_{\mathrm{t}}\right)$, and an indicator (or series of indicators) corresponding to the post-merger period (Post Merger $_{t}$ ). Using a reduced form pricing equation, there are two dominant identification approaches used to estimate the price effect of a merger. The first approach uses explicit controls for the cost and demand factors that affect prices independent of the merger. In these papers, the researcher explicitly specifies both the factors that affect a product's price and the functional form; i.e., the researchers explicitly specify $\gamma_{t}$ as a function of observed cost and demand factors.

An example of the first approach is the Chouinard and Perloff [2007] study of retail and wholesale gasoline price variation. The goal of this study is to determine the relative importance of different factors that affect gasoline prices over time, including increases in market power caused by mergers. Chouniard and Perloff use monthly state level gasoline pricing data from the U.S. Energy Information Agency (EIA) from March 1989 through June 1997. They include a large number of variables that likely determine the supply and demand of gasoline over time in different U.S. states $\left(\gamma_{\mathrm{t}}\right.$ in equation 1 above). Specifically, Chouinard and Perloff include variables that affect the demand for gasoline (including measures of income, weather, population, automobile ownership, and population density), input prices (crude oil prices, taxes, and controls for the type of pollution requirements in a given state), supply shocks (indicator variables for the first Persian Gulf war and refinery outages), and state fixed-effects (separate indicator variables allowing for a different price level in every state). Mergers are modeled as affecting price as in equation (1), a series of indicator variables for each merger where the indicator is equal to one in the post-merger time period for states affected by the merger.

For this approach to generate reliable estimates of the price effects of a merger, it is critical that the variables included in the econometric model (the supply and demand variables) control for all important factors that affect prices and that may be correlated 
with the timing of the merger. If some factor that is not included in the regression causes prices to rise (or fall) in the post-merger period, the researcher would mistakenly attribute this unobserved factor as the price effect of the merger. The validity of this approach depends on the application. There are many regional factors which are very difficult to observe (much less measure) that can have a large impact on gasoline prices. Because the supply and demand for gasoline are both very inelastic, unanticipated changes in output can have large effects on consumer prices. For example, in the summer of 2000 unanticipated decreases in output in the Midwest (caused primarily by unanticipated difficulties associated with meeting tighter environmental regulations) led to large price increases in the Midwest. ${ }^{6}$ While large shocks can be controlled for by including indicator variables in the estimating equation (as done by Chouniard and Perloff), smaller disruptions to the gasoline distribution network (pipelines, barges) can also lead to significant changes in regional prices which, while transitory, can last for weeks or even months. ${ }^{7}$ Thus, during the relatively short time horizon typically used to identify the price effect of a merger, one or two years, a cost shock could confound the ability to measure the price effect of a merger. The validity of this modeling approach depends critically on the ability to specify the factors that affect the prices of the products affected by the merger.

The second approach uses some form of a difference-in-difference estimator to identify the price effect of the merger and is the most common approach used in estimating the price effects of mergers. Instead of explicitly specifying the factors that change the demand and cost of a product over time $\left(\gamma_{t}\right)$, these studies identify a 'control' group of products that face similar demand and cost conditions to those potentially affected by a merger and then determine how those products prices change relative to the products sold in markets affected by a merger. Specifically, assume that the process

\footnotetext{
${ }^{6}$ Prices increased in Chicago and throughout the Midwest by nearly 60 cents a gallon in a little over a month, while more distant regions (connected by pipeline) experienced much smaller changes in price. See Bulow et al. [2003]. Despite facing identical input (crude oil) costs, supply shocks in gasoline markets can lead to large changes in relative prices that can take weeks to dissipate.

${ }^{7}$ The price effects of a number of localized supply shocks are shown in Chapter 4 of United States Federal Trade Commission (2005).
} 
causing prices to change over time in the control market is identical to that of the treatment market but for the price effect caused by the merger as in equation (2) below.

$$
\text { (2) } \mathrm{p}_{\mathrm{Ct}}=\alpha_{C 0}+\gamma_{\mathrm{t}}+\varepsilon_{\mathrm{Ct}}
$$

In equation (2) prices of the control product are allowed to be different than those of the product affected by the merger by a constant amount $\left(\alpha_{\mathrm{C} 0}\right)$, however, time varying factors affect prices in an identical manner as for the product affected by the merger. This leads to the estimating equation (3) which is the difference of equations (1) and (2).

$$
\text { (3) } \mathrm{p}_{\mathrm{Mt}}-\mathrm{p}_{\mathrm{Ct}}=\left(\alpha_{\mathrm{M} 0}-\alpha_{\mathrm{C} 0}\right)+\alpha_{\mathrm{M} 1} \text { Post }_{\text {Merger }}{ }_{\mathrm{Mt}}+\left(\varepsilon_{\mathrm{Mt}}-\varepsilon_{C t}\right)
$$

In equation (3) the intercept has the interpretation of being the difference in the premerger price between the product affected by the merger and the control product, and the error term is the difference in the error terms in the two cities. Under the assumption that the factors that causes prices to change for the two products are identical $\left(\gamma_{t}^{M}=\gamma_{t}^{C}=\gamma_{t}\right)$, this estimating equation yields the correct estimate of the price effect of the merger, $\alpha_{\mathrm{A} 1}$. The difficulty of the difference-in-difference approach is in identifying a good control product (or group of products ${ }^{8}$ ) for the products produced by the merging firms. In an antitrust setting, for example, there is often a tension between finding products that are in different geographic markets and therefore not affected by the transaction, while truly facing similar demand and cost conditions.

Kim and Singal (1995) estimate the price effects corresponding to a number of airline mergers using a difference-in-difference approach. They define a market as a citypair combination, for example, flights from Washington, DC to Chicago, Illinois. Their goal is to estimate the change in price on city-pairs where a merger reduced the number of competitors. A natural control group is a market containing the same number of competitors pre-merger with no reduction in competition post-merger. By using this control group Kim and Singal are implicitly assuming that the factors that may cause airline prices to change over time independent of the merger, such as jet fuel prices or changes in wage rates, will affect merger markets and control markets similarly. In their

\footnotetext{
${ }^{8}$ This example has been presented in terms of a single merging firm product and a single treatment product to provide easy intuition. In most applications, researchers estimate the price effects for multiple products using multiple controls.
} 
paper the price effect of the merger is calculated as the (percentage) change in fares in markets affected by the merger relative to the change in fares in control markets.

In many industries the approach used by Kim and Singal, of identifying a control market as a separate region selling identical products that is unaffected by the merger is not feasible. Ashenfelter and Hosken (2008), for example, are interested in estimating the price effects resulting from five mergers of firms producing branded consumer products in the motor oil, breakfast syrup, ready-to-eat cereal, feminine hygiene products, and distilled spirits industries. They observe retail prices for each brand sold in an industry across different regional markets before and after each merger occurred. Because each of these products is sold nationally, they cannot use prices of the same products sold in different regions as a control. Instead, Ashenfelter and Hosken use private label products (products in the same industry sold under a retailer's brand name) as a control group. The key assumption for estimating the price effect of the merger in this context is that the merging brands' prices would have changed in the same way as private label products in the absence of the merger. Private label products have nearly all of the same production costs as branded products, except advertising. For this reason, Ashenfelter and Hosken suggest that exogenous supply or demand shocks affecting the industry should affect private label and branded products' prices similarly. Further, private label products are likely relatively distant substitutes to the branded products produced by the merging parties. Thus, we would not expect private label products to increase in price in response to an anticompetitive price effect generated by the merger. However, even if private label products are important substitutes for the branded products, the bias introduced by failure of the modeling assumption can likely be signed if firms compete in prices. Davidson and Deneckere (1985) analyze the price effects of mergers using the static Bertrand model which underlies most unilateral effects analysis. They show that for most common demand systems, firms producing substitute products to those of the merging firms will increase their prices following a price increase by the merging firms. Thus, at worst, comparing the change in the prices of the merging firms' 
products to the change in private label prices will underestimate the effect of the merger if the underlying model is Bertrand. ${ }^{9}$

Whether it is best to control explicitly for supply and demand factors in estimating equation (1) or to identify a control product and estimate the price effects of the merger using a difference-in-difference estimator like equation (3) depends on characteristics of the merger being studied. It is often difficult to identify variables that measure the factors that affect a product's price over time. For this reason, when analyzing mergers where a good control product is available, for example, estimating the price effects of an airline merger, a difference-in-difference estimator is likely best. Even in these situations, however, a researcher should consider alternative controls where feasible to validate the assumption that the control and merger product face similar demand and supply shocks. In industries where there is no obvious control, a researcher must identify the price effects of the merger by explicitly controlling for those factors affecting supply and demand in the estimating equation. For example, many mergers in gasoline markets affect all cities in a region, and cities in regions unaffected by the merger may have different sources of supply and face different demand shocks (for example, weather). In this situation the best method for modeling the counterfactual would be to specify a model like that in Chounaird and Perloff.

\section{Price Measure}

Defining relevant products and their corresponding prices is almost always an important issue in antitrust analysis. For example, even within relatively homogenous product categories, such as the retail sale of gasoline, prices can vary substantially within a region. In order to describe the retail price of gasoline in a market some aggregation over products (gasoline sold at different retail outlets) is necessary. Price measurement too can be an important issue in merger retrospectives. Researchers are constrained by available data. Publically available data often contains a subset of transactions in the market. Data corresponding to that subset may (or may not) be sufficient to determine

\footnotetext{
${ }^{9}$ The result that rivals firms' prices increase from the pre-merger equilibrium to the post-merger equilibrium in Bertrand models with product differentiation depends upon properties of the demand curve and the shape of the marginal cost curve. If marginal costs are constant or increasing, a sufficient condition is that the cross derivative of demand is small.
} 
the price effects of the merger. The importance of price measurement can best be illustrated by examining recent studies estimating the price effects of mergers in the petroleum industry.

The U.S. petroleum industry has undergone dramatic change over the last 15 years. Many well known petroleum firms have merged, including Exxon and Mobil, Conoco and Phillips, and Marathon and Ashland. At the same time, many large petroleum firms have divested a substantial number of refineries to entrants and rivals. This merger activity in combination with dramatic volatility in the price of gasoline has led to concerns that these mergers may have harmed consumers. A number of recent studies have estimated the price effects of mergers affecting the gasoline industry. Some of these studies have focused on wholesale prices (Hastings and Gilbert 2004, GAO 2004) while others have focused on retail prices (Simpson and Taylor 2008, Hastings 2004) or both retail and wholesale prices (Chouinard and Perloff 2007, Taylor and Hosken 2007). On initial inspection, the choice of price measure might not appear important in evaluating mergers in gasoline markets. If a merger increased market power in the market for either the refining or distributing gasoline, then wholesale prices should increase. The wholesale price increase, in turn, should be passed on to retail prices. If retail markets are very competitive, we would expect something close to one-to-one pass thru of wholesale prices to retail prices.

Some institutional factors in gasoline markets complicate this hypothesized relationship between observed wholesale and retail prices. First, the specific wholesale price a gasoline retailer faces is determined by the vertical relationship between the retailer and the refiner supplying its gasoline. There are four primary types of arrangements between gasoline retailers and suppliers, two of which are publically observable. Gasoline stations that are independently owned and operated typically have the right to purchase gasoline at any wholesale distribution point. If a gasoline station of this type sells a specific brand of gasoline, for example, Exxon, that station must purchase that brand of gasoline. A station selling gasoline under its own name can purchase a generic gasoline. These prices are typically referred to as branded and 
unbranded "rack prices"10 and are the only wholesale gasoline prices that are observable at high frequency (daily or weekly) for relatively narrow geographic regions (metropolitan areas). Stations that are owned by a refiner but operated by a third party (lessee-dealer stations) also pay an unobserved wholesale price that may vary by station within a metropolitan area (often called a DTW price). ${ }^{11}$ Finally, some gasoline stations are owned and operated by a refiner. In this case the refiner directly determines the retail price, and the wholesale price is inherently unobservable. Second, these different wholesale gasoline prices change relative to each other over time. For instance, during supply disruptions refiners often increase the wholesale price charged to retail outlets unaffiliated with their brand relative to the price charged to stations selling their own brand of gasoline, see Bulow et al. (2003). Similarly, DTW prices change relative to rack prices during supply disruptions, see Taylor and Hosken (2007). Thus, at any point in time it is unclear which wholesale price (rack, branded rack, DTW, lessee dealer or unobserved transfer price facing refiner owned and operated stations) is the most relevant wholesale price in determining the retail price in a market.

The choice of price measure can lead to different conclusions about the price effects of a merger. In 2004 the GAO issued a report analyzing the price effects of a number of mergers in the petroleum industry. Their study examined how branded and unbranded rack prices changed in response to mergers. The GAO found that the combination of Marathon and Ashland Petroleum caused a wholesale price increase. Taylor and Hosken (2007) also analyzed the price effects of this merger and examined both retail and rack prices. Like GAO, Taylor and Hosken found that the observed wholesale price (rack price) increased, however, they did not find evidence of a retail price increase. In fact, Taylor and Hosken find evidence that the observed increase in rack prices may have reflected a change in the relative size of the different wholesale

\footnotetext{
${ }^{10}$ These wholesale prices are referred to as rack prices in the industry because they are the price charged at the truck rack where the gasoline is pumped into a delivery truck.

${ }^{11}$ This is often called a dealer-tank-wagon (DTW) price because the price of gasoline typically includes a delivery charge. Some independently owned stations enter into long term supply agreements with a refiner and pay a DTW price for gasoline.
} 
prices. $^{12}$ Thus, this merger increased some, but not all wholesale prices and, on net, this change in wholesale prices did not cause retail prices to increase.

While the above example is specific to the gasoline industry, most markets have idiosyncratic features that complicate price measurement. In the hospital industry there are dramatic differences in the costs of serving patients depending on the type of care they receive. In the retrospective analyses of hospital mergers researchers devote substantial effort to controlling for these costs. Otherwise, they would not be able to determine if prices increased (or decreased) following a merger as a result of an increase in market power or a change in the composition of the patients treated by the hospital. ${ }^{13}$ Similarly, airlines charge many different prices for tickets on flights, often in response to flight specific demand shocks. Researchers must carefully model this variation to avoid inadvertently attributing a supply or demand shock to a merger effect.

\section{Determining Pre and Post Merger Prices}

To measure the price effects of a merger, a researcher must specify the time periods corresponding to the pre and post merger time period. The goal is to identify a time period sufficiently long to capture any change in price associated with the change in market structure, but short enough to avoid any contaminating effects from other changes in the market. The pre-merger time period corresponds to the period directly proceeding the date at which firms change their pricing behavior. While the HSR Act requires that the merging firms to operate independently during the government's review of the merger, there is empirical evidence from both the banking (Prager and Hannan, 1998) and airline (Kim and Singal, 1993) industries that the merging firms increase their prices before the merger is consummated. In other industries firms may be limited in their ability to change price for a significant time period following the merger. Hospital prices, for example, are determined by contracts negotiated between hospitals and insurance companies for fixed time periods. Following a merger, a hospital's price will move to its post-merger level as its contracts with insurers are updated over time. For

\footnotetext{
${ }^{12}$ Taylor and Hosken note that DTW prices fell relative to observed rack prices suggesting that not all retailers felt a wholesale price increase.

${ }^{13}$ This issues is addressed at length in three recent hospital merger retrospectives Hass-Wilson and Garmon (2009), Tenn (2008), and Thompson (2009).
} 
this reason researchers often exclude pricing for some period following a merger to obtain a more precise measure of the post-merger price, see, for example, Tenn (2009). In some cases where the merger leads to a discrete change in the level of prices, the event date might be determined through conventional structural break tests with unknown break date (see for example Andrews and Ploberger, 1994 and Bai and Perron, 2006). Alternatively, when the date at which the merged firm begin coordinating their pricing behavior is unknown and the researcher has a relatively long price series, observations near the consummation date could be dropped to generate reliable estimates of pre- and post-merger pricing, see, for example, Ashenfelter and Hosken (2008).

\section{Selection Issues}

It is impossible to obtain a representative sample of all mergers because the government will attempt to block or modify those transactions believed to be anticompetitive. This creates a challenge to both estimating the effects of a merger on price and evaluating whether enforcement activity is at its proper level (Carlton, 2008). One approach to solving this problem is to focus on mergers that appeared to be on the enforcement margin. This is the approach of Ashenfelter and Hosken (2008). They identified five consumer product mergers that involved large firms operating in already highly concentrated industries. While it may be that many approved mergers result in no competitive harm, four of the five mergers analyzed in their study resulted in moderate but statistically significant price increases.

\section{Retrospective Studies for Merger Forecast Evaluation}

Antitrust policy towards horizontal mergers in the U.S. is largely prospective: regulators attempt to block those mergers predicted to increase price. A growing number of papers have estimated the effects of different mergers on prices. Unfortunately, given the heterogeneity across industries the number of merger retrospectives is far too small to make any inference on which market characteristics are correlated with price effects. It is currently impossible to generalize from these studies to aid decision makers in developing current antitrust policy. Instead, antitrust economists have relied on merger simulations, financial event studies, and retrospective studies of non-merger changes in 
market structure to inform antitrust decisions. All of these approaches require the validity of some strong assumptions if they are to yield accurate predictions. Existing retrospective merger studies, however, can be used to evaluate the predictive ability of these different merger simulation methods. This section describes different methods used to forecast the effects of mergers and how retrospective evidence can be used to evaluate them.

When sufficient data is available, economists now commonly estimate static oligopoly models and then use these models to simulate the unilateral price effects of mergers in differentiated product markets. These models focus on the incentive to increase prices after a merger that results from the internalization of consumer substitution. Each firm has beliefs about the prices its rivals will choose and picks its own prices to maximize its profits given those beliefs, which are (in equilibrium) correct. When considering a price increase firms balance the benefit of larger margins on each product sold against the cost of lost consumers that switch to another product. It then follows that if two separate firms respectively sell products that are the first and second choice of many consumers, a merger reduces the cost of a price increase and hence results in higher prices. Models that formalize and then quantify this argument are known as “merger simulations”. This approach was first taken by Baker and Bresnahan (1985) and, because the key ingredients in these models are consumer substitution patterns, modified versions have tracked developments in the demand estimation literature. Key contributions to the literature include Hausman, Leonard, and Zona (1994), Werden and Froeb (1994), and Nevo (2000).

Simulating the price effects of a merger requires several strong assumptions. Formally, the magnitude of the price increase in a unilateral effects model depends upon assumptions on consumer preferences and how the firms' cost of producing a unit of its product varies with total output. Simulating a merger also requires statistical assumptions that are necessary to estimate demand functions. In addition, the standard unilateral effects model also assumes that price is the only locus of competition and that firms' pricing decisions are static and thus independent of time. The estimated model of oligopoly may predict inaccurate price effects of the merger if any of these assumptions are invalid. Despite the huge amount of resources dedicated to merger review, only two 
papers have used retrospective evidence to evaluate methods used to simulate mergers. Both of these papers have data covering a period before and after mergers took place. Using only pre-merger data that would be available during merger review, the price effects of the mergers are simulated. Direct retrospective estimates of the mergers are obtained by adding to the sample post-merger data and the models are evaluated by comparing the indirect, simulated price effects to the directly estimated retrospective price effects.

Peters (2006) evaluates merger simulation techniques by comparing the simulated and direct price changes from airline mergers. He uses two different demand systems for fares, an assumption that the marginal cost of a fare is constant, and the assumption of static price competition to simulate 6 airline mergers. While the direction of the bias depends on which of the two demand systems is used, the direct and the simulated price changes were on average 10 percentage points different from the actual price changes for both specifications. Further, the simulations reverse the rank order of observed price effects. In his study the merger predicted to generate the largest price increase (Northwest/Republic) yielded the smallest observed price increase. Similarly the merger predicted to generate one of the smallest price effects (Continental/People's Express) generated the largest price increase.

Weinberg and Hosken (2008) evaluate merger simulations with retrospective evidence using data before and after two branded consumer product mergers occurred. They examined the merger of Pennzoil and Quaker State brand motor oils and an acquisition that combined Log Cabin and Mrs. Butterworth brand breakfast syrups. Both of these mergers are particularly well suited to the assumptions required by the standard merger simulation: the products were well known to consumers, and there was no recent entry, exit, or product repositioning of any importance in either industry. The results are similar to those of Peters in that the simulations reverse the rank order of the price effects. Retrospective evidence reveals the motor oil merger was marginally anticompetitive while the syrup merger had no impact on prices. The simulated price changes, on the other hand, were small for the motor oil merger and quite large in many specifications for the syrup merger. 
Another method for forecasting the competitive effects of potential mergers is the financial event study approach of Eckbo (1983) and Stillman (1983). The Eckbo and Stillman financial event studies of mergers examine the abnormal stock market returns of close competitors of the merging parties to determine if a merger is anticompetitive or not. Assuming that financial markets are efficient so current stock prices incorporate all available information, events that impact the probability of a potential merger occurring will change current stock market returns in a way that identifies the competitive nature of the merger. On one hand, an anticompetitive merger will increase rival firms future profits' and thus increase the value of their equity. On the other hand, a merger that lowers the marginal cost functions of the merging firms will decrease rival firms' future profits and lower the value of their equity. Therefore financial event studies provide a forecast of whether a merger will be anticompetitive or not, but do not forecast the magnitude of the merger's price effect.

McAfee and Williams (1988) evaluate the ability of financial event studies to predict whether mergers are anticompetitive with a case study. They analyze the 1979 merger of two microfilm producers, Xidex Corporation and Kalvar Corporation. In an earlier paper, Barton and Sherman (1984) found that this merger led to large price effects. Therefore, if the predictions of financial event studies are accurate, pre-merger events that increased (decreased) the likelihood of the merger occurring should have led to positive (negative) abnormal returns of rival firms. However, McAfee and Williams find that in most cases the exact opposite effects were found and that for nearly all specifications any merger effect from the financial event study was statistically insignificant. They argue that financial event studies had little power because the merging firms in this study received only a small portion (less than 8 percent) of their total revenues from markets affected by the merger. More evaluation studies like this of mergers of firms with overlap in product markets accounting for larger portions of their revenue would be valuable.

In some cases past changes in market structure such as entry and exit of firms provide an alternative to merger simulation for forecasting the price effects of a merger. This type of analysis was presented by both parties in the proposed merger between the office supply retailers Staples and Office Depot and is described in Ashenfelter et al. 
(2006). The central evidence in this case was that prices were lower in geographic markets where both Staples and Office Depot operated than in markets in which only one of the two firms was present. While suggestive, this observation is not persuasive by itself because whether both Staples and Office Depot or only one of the two were in a market is likely systematically related to other unobservable determinants of price such as costs or demand. In light of this, the government used entry and exit to identify the effect of market structure on price. If Staples would remove Office Depot from markets in which both firms compete after the merger was completed and there are historical instances of Office Depot exiting local markets where Staples also competed, then data on prices across different markets before and after exit occurred can be used to estimate the merger effect. If entry and exit of Office Depot impact price in equal but opposite directions, then both entry and exit events could be used. The key assumption needed to identify the effect of market structure on prices using entry and exit is that all unobservable determinants of price are constant over time within a market. If a firm exiting the market affects prices differently from a merger, then entry and exit are not symmetric, or entry and exit are driven by other unobservable changes in demand or cost In this situation a study of entry or exit may yield biased estimates of the effect of a merger on prices. To our knowledge no one has used post merger data to evaluate this modeling approach. ${ }^{14}$

\section{Conclusions}

Effective horizontal merger policy requires antitrust agencies to forecast the effects of mergers on consumer welfare. Despite more than thirty years of active horizontal merger enforcement following the passage of the Hart-Scott-Rodino act, there is relatively little empirical evidence to guide policy makers on how mergers affect competition. Antitrust enforcers and the courts largely rely on the testimony of economic experts, customers, company executives and company documents to forecast the impact of a merger on consumer welfare. We believe that this information, while extremely useful, should be supplemented by gathering more evidence on the price effects of

\footnotetext{
${ }^{14}$ In a recent study Manuszak and Moul (2008) also estimate a reduced form pricing equation for Staples which allows for the endogeniety of market structure and find qualitatively similar results to Ashenfelter et al.
} 
consummated mergers. By focusing on mergers that were on the enforcement margin, researchers can begin to develop empirical evidence on which types of mergers are likely to be problematic and can provide useful guidance to aid merger enforcement. More generally, economists have developed a number of models that predict the competitive effects of mergers. Merger retrospectives can also be used to evaluate and potentially improve these tools. 


\section{References}

Andrews, Donald W.K. and Werner Ploberger, "Optimal Tests When a Nuisance Parameter is Present Only Under the Alternative," Econometrica, 1994, 62 (6), $1383-1414$.

Ashenfelter, Orley C. and Daniel S. Hosken, "The Effect of Mergers on Consumer Prices: Evidence from Five Selected Case Studies," NBER Working Paper, 2008, (W13859).

, David Ashmore, Jonathan Baker, Suzanne Gleason, and Daniel S.

Hosken, "Empirical Methods in Merger Analysis: Econometric Analysis of Pricing in FTC v. Staples," International Journal of the Economics of Business, 2006.

Bai, Jushan and Pierre Perron, "Estimating and Testing Linear Models with Multiple Structural Changes," Econometrica, 1996, 66 (8), 47-78.

Baker, Jonathan B. and Timothy F. Bresnahan, "The Gains from Merger or Collusion in Product-differentiated Industries," Journal of Industrial Economics, June 1985, $33(4), 427-44$.

Barton, David M. and Roger Sherman, "The Price and Profit Effects of Horizontal Mergers: A Case Study," Journal of Industrial Economics, 1984, 38 (2), 165-177.

Bulow, Jeremy I., Jeffrey H. Fischer, Jay S. Creswell Jr., and Christopher T. Taylor, "U.S. Midwest Gasoline Pricing and the Spring 2000 Price Spike," The Energy Journal, 2003, 24 (3), 121-149.

Carlton, Dennis, "The Need to Measure the Effect of Merger Policy and How to Do It," Competition Policy International, 2009.

Chouinard, Hayley and Jeffrey M. Perloff, "Gasoline Price Differences: Taxes, Pollution Regulations, Mergers, Market Power, and Market Conditions," The B.E. Journal of Economic Analysis and Policy, 2009.

Deneckere, Raymond and Carl Davidson, "Incentives to Form Coalitions with 
Bertrand Competition," The RAND Journal of Economics, 1985, 16, 473-86.

Eckbo, B. Espen, "Horizontal Mergers, Collusion and Stockholder Wealth," Journal of Financial Economics, 1983, 11, 241-273.

FTC, "Gasoline Price Changes: The Dynamic of Supply, Demand, and Competition," Technical Report, United States Federal Trade Commission 2005.

GAO, "Effects of Mergers and Market Concentration in the U.S. Petroleum Industry," Report to the Ranking Minority Member, Permanent Subcommittee on Investigations, Committee on Governmental Affairs, U.S. Senate, United States General Accounting Office May 2004.

Hass-Wilson, Debra and Christopher Garmon, "Two Hospital Mergers on Chicago's North Shore: A Retrospective Study," Bureau of Economics Working Paper, Fedral Trade Commission 2009.

Hastings, Justine S., "Vertical Relationships and Competition in Retail Gasoline Markets: Empirical Evidence from Contract Changes in Southern California," American Economic Review, March 2004, 94 (1), 317-328. and Richard J. Gilbert, "Market Power, Vertical Integration, and the Wholesale Price of Gasoline," Journal of Industrial Economics, December 2005, 53 (4), 469-492. Hausman, Jerry A., Gregory K. Leonard, and J. Douglas Zona, "Competitive Analysis with Differentiated Products," Annales D'Economie et de Statistique, 1994, $34(1), 159-180$.

Hunter, Graeme, Gregory K. Leonard, and Steven Olley, "Merger Retrospective Studies: A Review," Antitrust, 2008, 23, 34-41.

Kim, E. Han and Vijay Singal, "Mergers and Market Power: Evidence from the U.S. Airline Industry," American Economic Review, 1993, 83, 549-569.

Manuszak, Mark D. and Charles C. Moul, "Prices and Endogenous Market Structure in Office Supply Superstores," Journal of Industrial Economics, 2008, 56. 
McAfee, R.P. and M.A. Williams, "Can Event Studies Detect Anticompetitive Mergers?," Economics Letters, 1988, 28, 199-203.

Nevo, Aviv, "Mergers with Differentiated Products: The Case of the Ready-to-Eat Cereal Industry," The RAND Journal of Economics, 2000, 31 (3), 395-421.

Pautler, Paul, "Evidence on Mergers and Acquisitions," Antitrust Bulletin, 2003, 48 (1), 119 .

Peters, Craig, "Evaluating the Performance of Merger Simulations: Evidence from the U.S. Airline Industry," Journal of Law and Economics, 2006, 49, 627-649.

Prager, Robin A. and Timothy H. Hannan, "Do Substantial Horizontal Mergers Generate Significant Price Effects? Evidence from the Banking Industry," Journal of Industrial Economics, December 1998, 46 (4), 433-52.

Simpson, John and Christopher T. Taylor, "Do Gasoline Mergers Affect Consumer Prices? The Marathon Ashland Petroleum and Ultramar Diamond Shamrock Transaction," Journal of Law and Economics, 2008, 51 (1), 135-52.

Stillman, R., "Examining Antitrust Policy Towards Horizontal Mergers," Journal of Financial Economics, 1983, 11, 225-240.

Taylor, Christopher T. and Daniel S. Hosken, "The Economic Effects of the Marathon-Ashland Joint Venture: The Importance of Industry Supply Shocks and Vertical Market Structure," Journal of Industrial Economics, 09 2007, 55 (3), 419-451.

Tenn, Steven, "The Price Effects of Hospital Mergers: A Case Study of the Sutter-Summit Transaction," Bureau of Economics Working Paper, Fedral Trade Commission 2008.

Thompson, Aileen, "The Effects of Hospital Mergers on Inpatient Prices: A Case Study of the New Hanover Cape Fear Transaction," Bureau of Economics Working Paper, Fedral Trade Commission 2009.

Weinberg, Matthew C., "The Price Effects of Horizontal Mergers," Journal of 
Competition Law and Economics, July 2008, 4 (2), 433-47. and Daniel Hosken, "Using Mergers to Test a Model of Oligopoly," Working Paper, University of Georgia 2008.

Werden, Gregory J. and Luke M. Froeb, "The Effects of Mergers in Differentiated Products Industries: Logit Demand and Merger Policy," Journal of Law, Economics and Organization, October 1994, 10 (2), 407-26. 